ISSN (e)-2347-176x ISSN (p) 2455-0450

crossref DOI: https://dx.doi.org/10.18535/jmscr/v7i7.03

\title{
A Comparative Study of Intraperitoneal Instillation and Periportal Infiltration Of $0.5 \%$ Or $0.75 \%$ Ropivacaine with Dexmedetomidine as Adjuvant for Post Operative Analgesia in Laparoscopic Cholecystectomy
}

Authors

Kanta Bhati $^{1}$, Vandana Bhatnagar ${ }^{2 *}$, Mohd. Yunus Khilji ${ }^{3}$, Naresh Kumar Sharma ${ }^{4}$

${ }^{1}$ Professor and Head, ${ }^{2}$ Resident, ${ }^{3}$ Associate Professor, ${ }^{4}$ Senior Resident

*Correspondence Author

Vandana Bhatnagar

Department of Anaesthesia, Sardar Patel Medical College \& AGH, Bikaner, Rajasthan, India

\begin{abstract}
Aim and Objectives: To compare the analgesic efficacy and safety of two different concentration of ropivacaine with dexmedetomidine as adjuvant by intraperitoneal instillation and port site infiltration, for post-operative analgesia in laparoscopic cholecystectomy under General Anaesthesia.

Material and Method: 90 patients of ASA grade I and II aged 18-65 years, randomly allocated in 3 group in this prospective randomized controlled double blind study. In group-I 0.9\% Normal saline(40 ml), In group -II $0.5 \%$ Ropivacaine $(20 \mathrm{ml})+$ Dexmedetomidine $(1 \mathrm{mcg} / \mathrm{kg})$ and in group-III, 0.75\% Ropivacaine $(20 \mathrm{ml})+$ Dexmedetomidine $(1 \mathrm{mcg} / \mathrm{kg})$ were taken and diluted with saline up to $40 \mathrm{ml} .20 \mathrm{ml}$ instilled intraperitoneally before removing trocar and $20 \mathrm{ml}$ infiltered at port site after removal of trocar. All patients were assessed for VAS Score, duration of analgesia, total analgesic consumption in 12 and 24 hrs and any adverse effects or complication in postoperative period.

Results: Duration of analgesia ( $h r s)$ was longer with $0.75 \%$ ropivacaine (6.5 \pm 3.06 ), as compared to $0.5 \%$ ropivacaine $(4.07 \pm 2.42)$ and control group $(0.725 \pm 0.31)$

Total analgesic consumption in 12 and 24 hours was lesser with $0.75 \%$ ropivacaine $(1 \pm 0.45,1.43 \pm 0.72)$ as compare to $0.5 \%$ ropivacaine $(1.13 \pm 0.57,1.76 \pm 0.77)$ and control group $(2.3 \pm 0.46,3.53 \pm 0.5)$

Conclusion: Intra-peritoneal instillation and port site infiltration of $0.75 \%$ Ropivacaine with dexmedetomidine provides superior and prolonged pain relief without any adverse effects, making its use simple safe and effective for postoperative analgesia in laparoscopic cholecystectomy.

Keywords: Ropivacaine, dexmedetomidine, Laparoscopic cholecystectomy.
\end{abstract}

\section{Introduction}

Laparoscopic cholecystectomy (LC) is the treatment of choice in treating Gall Bladder disease and it has improved surgical outcome in terms of reduced pain, morbidity, duration of convalescence, better cosmetic results and shorter hospitalisation. ${ }^{1}$ Although it is a minimally invasive procedure but pain has been mentioned as major complain and a reason for delayed postoperative recovery.

The origin of pain after LC is multifactorial with different pain components secondary to different pain mechanisms: Somatic Pain- Pain from incisional site, Visceral Pain- pain from intra- 
abdominal trauma due to gall bladder removal and referred shoulder pain- due to diaphragmatic irritation caused by residual $\mathrm{CO}_{2}$ in peritoneal cavity.

Recently the use of local anaesthetics for postoperative pain relief after LC has become a popular technique and it is a part of multimodal approach to post operative pain management. ${ }^{2}$ The main advantage of using local anaesthetics is that it provides adequate analgesia without any considerable side effect unlike opioids which may delay recovery. ${ }^{3}$

Intra peritoneal instillation and port site infiltration of local anaesthetic agent in combination with dexmedetomidine provides effective and prolonged duration of postoperative analgesia in Laparoscopic Surgeries. ${ }^{4}$ So we have compared two different concentrations of Ropivacaine $\quad 0.5 \% \quad$ or $\quad 0.75 \%$ with dexmedetomidine $(1 \mathrm{mcg} / \mathrm{kg})$ as adjuvant to provide nearly total somatic and visceral pain block by instillation in peritoneal cavity and infiltration at port site in laparoscopic cholecystectomy.

\section{Method}

This Comparative prospective randomized controlled double blind hospital based study was conducted on 90 patients of ASA grade I \& II , 18 to 65 years of age \& both sexes undergoing elective laparoscopic cholecystectomy under general Anaesthesia after taking approval from Institutional Ethical committee and informed consent from patient and their close relatives. Patients with any chronic medical illness, allergic to study drug, pregnant and lactating women are excluded from the study.

Patients were randomly allocated into three groups In group-I 0.9\% Normal saline $(40 \mathrm{ml})$, In group II $0.5 \%$ Ropivacaine $(20 \mathrm{ml})+$ Dexmedetomidine $(1 \mathrm{mcg} / \mathrm{kg}$ ) and in group-III, $0.75 \%$ Ropivacaine $(20 \mathrm{ml})+$ Dexmedetomidine $(1 \mathrm{mcg} / \mathrm{kg})$ were taken and total volume made $40 \mathrm{ml}$ in each group diluting with saline.

Preanaesthetic check up was done and Visual analogue scale (VAS) for pain was explained to every patient. In OT multipara monitors were attached. Baseline SBP, DBP, SPO2, Pulse rate $\mathrm{EtCO}_{2}$ were recorded (T0). I.V line was secured with $20 \mathrm{G}$ cannula and patient preloaded with ringer lactate $5 \mathrm{ml} / \mathrm{kg}$ intravenously. Patient received inj. glycopyrrolate $(0.005 \mathrm{mg} / \mathrm{kg})$ and ondansetron $(.01 \mathrm{mg} / \mathrm{kg})$ intravenously 30 minutes prior to administration of anaesthesia and inj. fentanyl $(2 \mu \mathrm{g} / \mathrm{kg})$ intravenously just before induction. Inj. propofol $(2 \mathrm{mg} / \mathrm{kg})$ i.v. given for induction and vecuronium $(0.1 \mathrm{mg} / \mathrm{kg})$ to facilitate tracheal intubation. Anaesthesia maintained with $0.5 \%$ to $1 \%$ isoflurane. Adequate muscle relaxation achieved with vecuronium bromide $(0.01 \mathrm{mg} / \mathrm{kg})$. Ventilation (tidal volume $8-10 \mathrm{ml})$ was adjusted to maintain end tidal $\mathrm{CO} 2$ below 38 $\mathrm{mmHg}$. Patients was placed in $15^{\circ}$ to $20^{\circ}$ reverse trendelenberg position. During laparoscopy, intra abdominal pressure was maintained at 12-14 $\mathrm{mmHg}$. The $\mathrm{CO} 2$ was carefully evacuated at the end of surgery by manual compression of abdomen with open trocar. Study drug according to group was instilled intraperitoneally $(10-10 \mathrm{ml}$ in left and right subdiaphragmatic region) before removal of trocar and $20 \mathrm{ml}$ infiltrated at port site $(6 \mathrm{ml}$ at umblical incision , $6 \mathrm{ml}$ at epigastric incision and $4 \mathrm{ml}$ at both working port each) after removal of trocar.

The postoperative pain was assessed using 10 point VAS at, 30 mins, 1, 2, 4, 6, 8 and $12 \mathrm{hrs}$ in post-operative period. Inj, diclofenac aqueous (75 mg IV) was given when VAS > 4, as rescue analgesic. Time to first analgesic requirement, total analgesic consumption in the first 12 and 24 hours and any complication and side effects were noted in postoperative period. Haemodynamic parameters (SBP, DBP, MBP, Pulse, SPO2)- were recorded at, 30 mins, 1, 2, 4,6,8and $12 \mathrm{hrs}$ postoperatively. Patient was regularly monitored for episodes of hypotension (MAP $<60 \mathrm{mmHg}$ ), and bradycardia $(\mathrm{HR}<60 \mathrm{bpm})$ in post-operative period.

\section{Statistical Analysis}

pre structured pre tested proforma was used for Data collection and for data analysis microsoft 
excel and statistical software SPSS version 22.0 was used and data were analysed with the help of percentage, mean, SD in the form of tables, diagrams and tests of significance (Chi-square test ,student $\mathrm{t}$ test and ANOVA) were applied wherever required.

\section{Results}

Demographical datas were Statistically comparable. (Table-1). Baseline haemodynamic parameters were comparable and difference among the three groups was insignificant.

Mean VAS was lower in group III and group II than in group-I at all the time intervals. The difference between Group II and III was statistically significant at 4 hour $(2.5 \pm 0.98$ vs $2.33 \pm 0.56)$, at 6 hour $(2.27 \pm 1.11$ vs $2.77 \pm 0.85)$ and at 8 hour $(1.7 \pm 1.05$ vs $2.27 \pm 1.29)$. (p value<0.05) $($ Table-2)

Duration of analgesia (hrs) was longer with Group III (6.5 \pm 3.06$)$, as compared to Group II $(4.07 \pm 2.42)$ and control group $(0.725 \pm 0.31)$ and the difference among the groups was statistically significant.(graph-1))

Total analgesic consumption in 12 and 24 hours was lesser with Group III $(1 \pm 0.45,1.43 \pm 0.72)$ as compare to Group II $(1.13 \pm 0.57,1.76 \pm 0.77)$ and control group $(2.3 \pm 0.46, \quad 3.53 \pm 0.5)$ Total analgesic consumption in 12 and 24 hours was lesser in Group-III than in Group II but the difference was not statistically significant. ( $p$ value> 0.05) (Graph-2)

Shoulder pain was not observed in any of the three groups in the first 8 hours postoperatively; however, after 8 hours, shoulder pain was observed in 6 patients in Group I (20\%). No shoulder pain was observed in patients receiving ropivacaine $(0.75 \%$ or $0.5 \%)$ with dexmedetomidine even after 8 hours postoperatively. Emetic symptoms were observed in 5 patients in Group I (16\%), 2 patients in Group II and III (6\% in each). Hypotension and bradycardia were observed in 2 patients in Group III (6\%), 1 patient in Group II (3\%) and not observed in Group I (0\%). Hypotension and bradycardia were self limiting and no clinical intervention required. Pruritus was observed in 2 ptients in Group I (6\%) and 1 patient in Group III $(3 \%)$ and pruritis was not observed in Group II $(0 \%)$. Pruritus was self limiting and no clinical intervention required.

Table-1 Demographic profile, ASA grade and duration of surgery

\begin{tabular}{|l|c|c|c|c|}
\hline Socio-demographic & Group-I & Group-II & Group-III & p-value \\
\hline Age(yrs) & $36.2 \pm 11.5$ & $37.23 \pm 11.98$ & $39.3 \pm 12.01$ & 0.580 \\
\hline Sex (M:F) & $0: 30$ & $5: 25$ & $2: 28$ & 0.053 \\
\hline Weight (Kg) & $56.9 \pm 4.18$ & $57.5 \pm 8.13$ & $56.63 \pm 6.23$ & 0.472 \\
\hline ASA(I:II) & $26: 4$ & $28: 2$ & $28: 2$ & 0.578 \\
\hline Duration of surgery (Mint) & $49.33 \pm 6.91$ & $49.67 \pm 6.14$ & $47.2 \pm 10$ & 0.423 \\
\hline
\end{tabular}

Table -2 Comparison of postoperative Mean VAS Scores

\begin{tabular}{|l|c|c|c|c|c|c|c|c|c|}
\hline \multirow{2}{*}{ Time } & \multicolumn{2}{|c|}{ Group-I } & \multicolumn{2}{c|}{ Group-II } & \multicolumn{2}{c|}{ Group-III } & \multicolumn{3}{c|}{ p-value } \\
\cline { 9 - 12 } & Mean & SD & Mean & SD & Mean & SD & I\&II & I\&III & II\&III \\
\hline T0 & 4.06 & 1.31 & 2.4 & 0.62 & 2.33 & 0.76 & 0.001 & 0.001 & 0.711 \\
\hline T1 & 4.07 & 0.82 & 2.3 & 0.61 & 2.2 & 0.7 & 0.001 & 0.001 & 0.558 \\
\hline T2 & 2.56 & 0.57 & 2.36 & 0.71 & 2.3 & 0.75 & 0.234 & 0.25 & 0.726 \\
\hline T3 & 2.6 & 0.51 & 2.5 & 0.98 & 2.33 & 0.56 & 0.107 & 0.471 & 0.041 \\
\hline T4 & 3.4 & 0.81 & 2.27 & 1.11 & 2.77 & 0.85 & 0.007 & 0.049 & 0.046 \\
\hline T5 & 3.23 & 1.04 & 1.7 & 1.05 & 2.27 & 1.29 & 0.001 & 0.069 & 0.02 \\
\hline T6 & 2.53 & 1.04 & 0.93 & 0.90 & 0.83 & 0.69 & 0.001 & 0.001 & 0.634 \\
\hline
\end{tabular}


Graph-1 Duration of analgesia (hours)

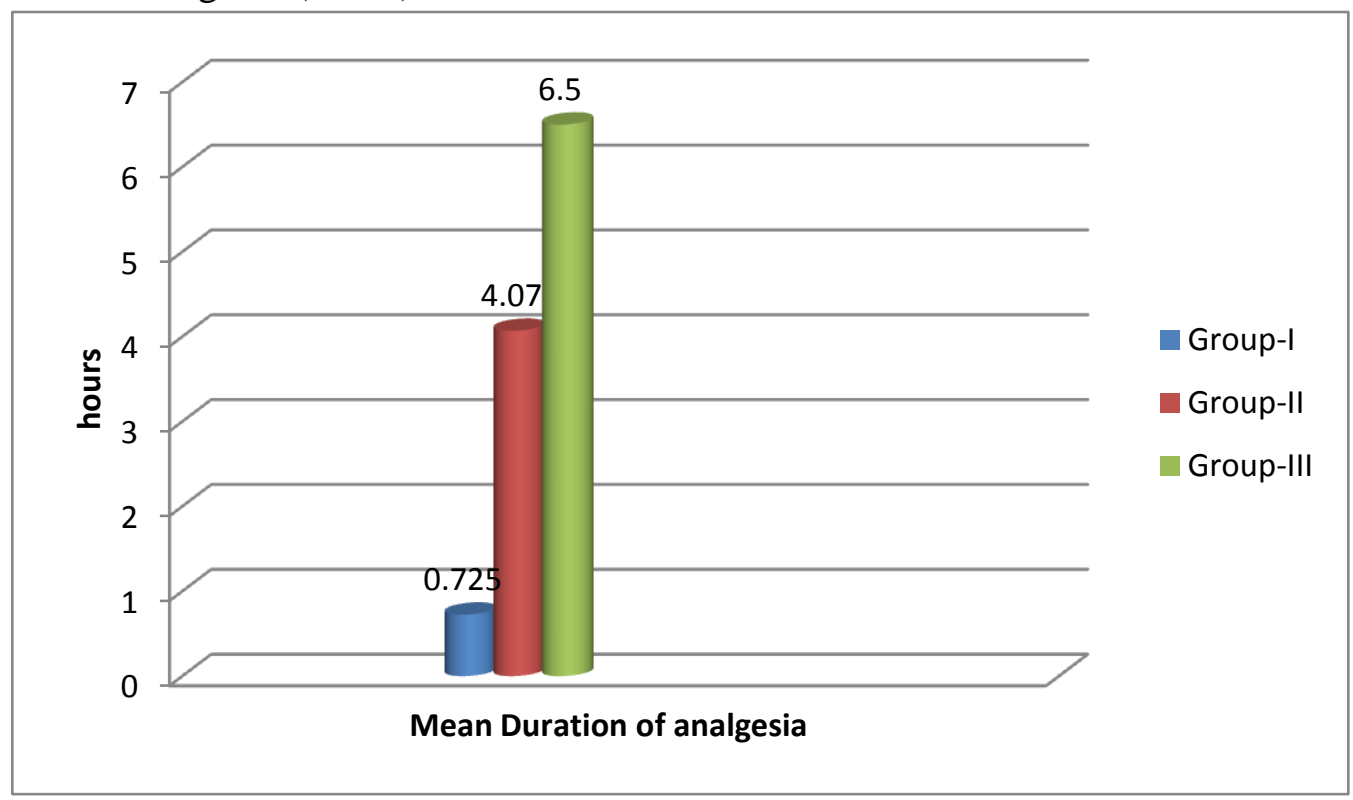

Graph-2 Total analgesic consumption

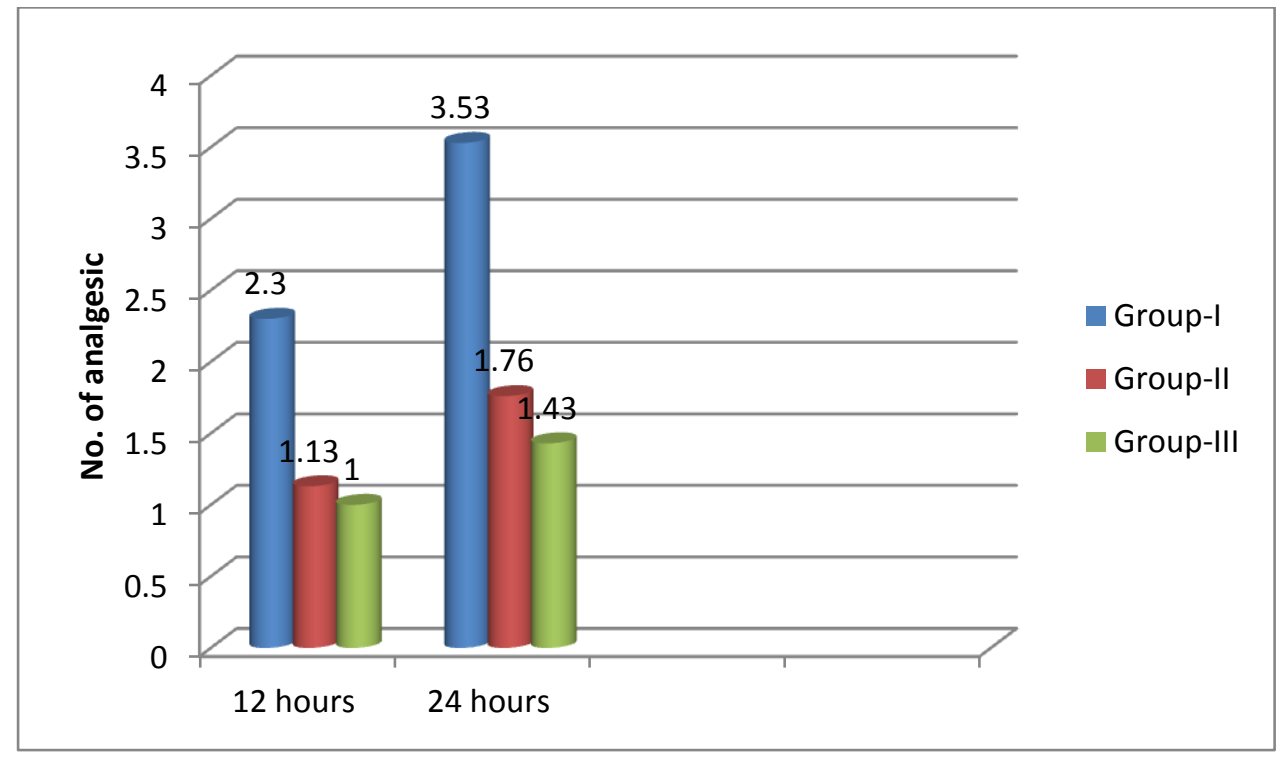

\section{Discussion}

The use of local anaesthetics for post-operative pain relief after LC has become a popular technique as a component of multi modal approach of postoperative pain management.

Mean VAS scores were lower in group II and III than in group I at all the time intervals. Ranjita Acharya et $\mathrm{al}^{5}$ found similar observations to our study that VAS scores are lower at all the time intervals with intraperitoneal ropivacaine $(0.2 \%)$ and dexmedetomidine group than in ropivacaine alone

.Group-III provided longer duration of analgesia than in Group II and Group I. Meena RK et $\mathrm{al}^{6}$. found that mean duration of analgesia with intraperitoneal instillation of $0.75 \%$ ropivacaine $(2 \mathrm{mg} / \mathrm{kg})$ was $2 \mathrm{hrs}$. We added dexmedetomidine $(1 \mathrm{mcg} / \mathrm{kg})$ to ropivacaine and also infiltrated drug at port site to block somatic component of pain to prolong the mean duration of analgesia which was $6.68 \mathrm{hrs}$ in our study. Shrinivas Rapolou et $\mathrm{al}^{7}$, also found that duration of analgesia was longer with intraperitoneal instillation of bupivacaine $(0.25 \%)$ and dexmedetomidine as compare to bupivacaine alone.

Total analgesic consumption in 12 and 24 hours was significantly lower in Group II and Group III than in Group-I and it was lesser in Group-III than 
in Group II but the difference was not statistically significant. Sunil Chiruvella et $\mathrm{al}^{8}$. also observed that the total analgesic consumption was lower in ropivacaine $(0.2 \%)$ with dexmedetomidine group as compare to ropivacaine alone group

Incidence of shoulder pain was higher in control group (20\%), none of the patient in Group II and III was complained of shoulder pain $(0 \%)$. Shoulder pain is a common outcome after LC and can delay return to normal activities. Incidence of shoulder pain after LC is $35 \%$ to $63 \%$ and maximum incidence occurs the night after surgery. The proposed mechanism of shoulder pain seems to be a diaphragmatic stretching with phrenic nerve neuropraxia, which is possibly due to increased concavity of diaphragm induced by pneumoperitoneum and referred pain from the traumatized area. Shoulder pain was not observed in any of the three groups in the first 8 hours postoperatively. The reason could be the blocking of nociceptive inputs generated by inflamed diaphragm and peritoneum by instillation of ropivacaine and dexmedetomidine. Higher incidence of emetic symptoms in control Group $(16 \%)$, could be due to higher pain scores and thus greater autonomic response..Similar findings were obtained by Kucuk et $\mathrm{al}^{9}$

Intraperitoneal LA is likely to block free afferent nerve endings in the peritoneum. Systemic absorption of local anaesthetic from the peritoneal cavity also play a part in reducing visceral pain. port site infiltration along with intra peritoneal instillation of Local Anaesthetic reduces somatic and visceral pain both, so we used both the routes in our study.

Observation of Dan-Shu lu et $\mathrm{al}^{10}$ are similar to our observations that Intraperitoneal and incisional ropivacaine exerts more powerful analgesic effect than intraperitoneal or incisional ropivacaine alone. A Singh et $\mathrm{al}^{11}$ found similar observation to our study that Intraperitoneal instillation of ropivacaine $(0.75 \%)$ with fentanyl reduces not only the intensity of visceral, parietal and shoulder pain but also the total rescue analgesic dose consumption. Dinesh Singh, et al. ${ }^{12}$ observed similar results to our study that intraperitoneal instillation of ropivacaine $(0.5 \%)$ provides good analgesia in the immediate postoperative period after laparoscopic surgery.

we added dexmedetomidine as adjuvant to ropivacaine in our study because dexmedetomidine synergise the action of LA and prolong the duration of postoperative analgesia . Dexmedetomidine is selective $\alpha-2$ adrenergic agonist with analgesic and sedative properties. The antinociceptive effect of dexmedetomidine is seen at dorsal root neuron level, where it blocks the release of substance $\mathrm{P}$ in the nociceptive pathway. Its use in combination with Ropivacaine is associated with prolongation of Local Anaesthetic effects.

\section{Limitations of study}

1) Pain is a subjective sensation and thorough objective observation of such is difficult.

2) The population enrolled was in the age group of 18-65 years which were otherwise healthy patients of ASA Grade I and II, so the effect of Dexmedetomidine as an adjuvant in older patients with cardiovascular co morbidities is yet to be investigated.

3) Total analgesic consumption could have been ascertained more precisely if the study were conducted for longer periods and sample size was large.

4) We did not record duration of hospital stay.It is really a key variable to measure health in economic term.

\section{Conclusion}

Intra-peritoneal instillation and port site infiltration of $0.75 \%$ Ropivacaine with dexmedetomidine provides superior and prolonged pain relief without any adverse effects, making its use simple safe and effective for postoperative analgesia in laparoscopic cholecystectomy.

\section{Reference}

1. Schirmer BD, Edge SB, Dix J, Hyser MJ, Hanks JB, Jones RS. Laparoscopic 
cholecystectomy. Treatment of choice for symptomatic cholelithiasis. Annuals of surgery. 1991 Jun;213(6):665.

2. Sukhyanti Kerai, Kirti Nath Saxena and Bharti Taneja. Post-caesarean analgesia: what is new? Indian journal anaesthesia. 2017 Mar; 61(3);200-2014.

3. Cha SM, Kang H, Baek CW, Jung YH, Koo GH, Kim BG, Choi YS, Cha S Cha YJ. Peritrocal and intraperitoneal ropivacaine for laparoscopic cholecystectomy: a prospective, randomized, doubleblind controlled trial. Journal of Surgical Research. 2012 Jun 15;175(2):251-8.

4. Labaille T, Mazoit JX, Paqueron X, Franco D, Benhamou D. The clinical efficacy and pharmacokinetics of intraperitoneal ropivacaine for laparoscopic cholecystectomy. Anesthesia \& Analgesia. 2002 Jan 1;94(1):100-5. .

5. Acharya R, Karan D, Khetan M. Postoperative analgesia with intraperitoneal ropivacaine with and without dexmedetomidine after total laparoscopic hysterectomy: a randomized, double-blind, controlled trial. asian j pharm clin res,2016; vol 9,suppl.3,2016, 76-79.

6. Meena RK, Meena K, Loha S, Prakash S. A comparative study of intraperitoneal ropivacaine and bupivacaine for postoperative analgesia in laparoscopic cholecystectomy: a randomized controlled trial. Anaesth Pain \& Intensive Care. 2016 Sep 1;20(3):295-302.

7. Rapolu S, Kumar KA, Aasim SA. A comparative study on intraperitoneal bupivacaine alone or with dexmedetomidine for post-operative analgesia following laparoscopic cholecystectomy. IAIM , 2016; 3(12): 33-40.

8. Chiruvella S, Nallam SR. Intraperitoneal instillation of ropivacaine plus dexmedetomidine for pain relief after laparoscopic hysterectomy: A comparison with ropivacaine alone. Journal of Dr.
NTR University of Health Sciences. 2016 Apr 1;5(2):93.

9. Kucuk C, Kadiogullari N, Canoler O, Savli S. A placebo-controlled comparison of bupivacaine and ropivacaine instillation for preventing postoperative pain after laparoscopic cholecystectomy. Surg Today. 2007; 37(5), 396-400. .

10. Liu DS, Guan F, Wang B, Zhang T. Combined usage with intraperitoneal and incisional ropivacaine reduces pain severity after laparoscopic cholecystectomy. International journal of clinical and experimental medicine. 2015;8(12):22460. 20

11. Singh A, Mathur SK, Shukla VK. Postoperative analgesia with intraperitoneal ropivacaine with and without fentanyl after laparoscopic cholecystectomy: a randomized doubleblind controlled trial. OA Anaesthetics. 2013;1:9.

12. Singh D, Bogra J, Saxena S, Chaudhary A, Bhusan S, Chandra G. The Effect of Intraperitoneal Ropivacaine for PostOperative Pain Management in Patients Undergoing Laparoscopic Cholecystectomy: A Prospective DoubleBlind Randomized Control Study. Open Journal of Anesthesiology. 2013 May 7;3(03):193. 